Anatoliy Kholodenko, Candidate of Economic Sciences, Associate Professor Odesa National Maritime University, 34, Mechnikov str., Odessa, 65029, Ukraine ORCID: 0000-0001-7626-5820

ResearcherID: B-4321-2019

Mariia Bashchak, Postgraduate

Odesa National Maritime University, 34, Mechnikov str., Odessa, 65029, Ukraine ORCID: 0000-0002-8455-9164

\title{
INTEGRATION OR PRICE COMPETITION IN THE SYSTEM OF TWO COMPETING HOTEL AND RESTAURANT BUSINESSES
}

This article discusses economical and mathematical modeling of the market behavior of hotel and restaurant business and their effective functioning. The corresponding models of integration and price competition in the system of two enterprises of the hotel and restaurant business are analyzed and constructed. It is revealed and substantiated that the optimal state of the hotel and restaurant business system can be realized only when they are combined (coordination of actions) or directly. On the basis of the conducted research it can be noted that the competition of the enterprises of the hotel and restaurant business is beneficial to the consumers of their services, but not profitable to the enterprises of the hotel and restaurant business. The publication provides a thorough and detailed analysis of the optimal, equilibrium and quasi-optimal states of the system of two enterprises of the hotel and restaurant business

Keywords: integration, price competition, hotel and restaurant business, economic and mathematical modeling, optimum, market behavior of enterprise, tourism modeling.

Relevance of research topic. The problem of integration or price competition in the system of two competing enterprises of the hotel and restaurant business is important for the enterprise itself, both for the consumer and for the economy of the country as a whole. The role of the hotel and restaurant business is contradictory and different from that of a conventional product manufacturer in classic microeconomic competition and integration models. On the one hand, the situation is complicated by 
product differentiation, on the other, the inability to reduce the price vectors of different hotel and restaurant businesses to a scalar. This is due to the relevance of our research.

Formulation of the problem. The problem is finding the optimal state of the system in which all participants, namely two competing companies and the consumer of their services, benefit from integration or price competition. This is accompanied by a number of differences of the hotel and restaurant business from the usual enterprise that produces products.

Analysis of recent researches and publications. Studies of the market behavior model of the hotel and restaurant business enterprises are reflected in publications and studies.

The serious interest in this problem is indicated by the appearance in recent years of a number of publications by such scientists: M. Bosovska, N. Vedmid, M. Kulyk [1]-diagnosis and structuring of the integration processes of tourism enterprises; T. Russell Crook, David J. Ketchen, Charles C. Snow [2]-competitive advantage: a strategic management model; M.Dibra [3]-study of factors influencing integration of sustainability in the tourism business; Adriana F. Chim-Miki, Rosa M. Batista [4]-development of a tourism coopetition model and the use of Delphi techniques; M. Bosovska [5]-integration processes in tourism,the monograph is devoted to theoretical, methodological and practical issues of the formation and development of integration processes in tourism; A. George Assafa, Mike G. Tsionasb [6]-scientific papers on the study and implementation of new methodological breakthroughs on tourism modeling; Fatemeh Ahmadimanesh, Mohammad Mahdi Paydar, Ebrahim Asadi-Gangraj[7]-designing a mathematical model for dental tourism supply chain; Anna Spenceley, Susan Snyman, Paul F.J. Eagles[8]-various models of tourism services management developed; Sanaz Shafiee, Ali Rajabzadeh Ghatari, Alireza Hasanzadeh, Saeed Jahanyan[9]-Tourism Management Perspectives; Libo Yan, Bo Wendy Gao, Meng Zhang [10]-a mathematical model for tourism potential assessment.

\section{General statement of the problem}

In classical competitors of microeconomic models and manufacturer integration, people [11-15] are well aware of both Cournot and Stackelberg's optimization and equilibrium. In these models, they control their figures, and they release from the aggregate value the desired market price.

In the case of hotel and restaurant businesses (which do not produce products but provide services; the fundamental difference here is that products can be produced before demand for them, under future demand; services can only be provided by those in demand already presented) primary is no longer the issue of products in one volume or another, but the establishment of a price (tariff) for services, and not necessarily the only one in all competing enterprises in the hotel and restaurant business. Demand for services of each enterprise of the hotel and restaurant business is also differentiated 
and depends on a set of prices of all enterprises in the hotel and restaurant business vector size, as opposed to the scalar sum of volumes of production in the classical case.

First production, then - depending on the demand for the volume produced setting the price of production; for enterprises in the hotel and restaurant business: first setting the price for services, then - depending on the demand at these prices - the provision of services), but also fundamentally complicated - due to product differentiation (services of different enterprises in the hotel and restaurant business are interchangeable, but still not identical, differ in quality, place of delivery I, therefore, for the services of each enterprise of the hotel and restaurant business has its own function of demand) and the inability to reduce the vector of prices of different enterprises of the hotel and restaurant business to a scalar.

First, for simplicity, we consider the case where the system consists of two alternative hotel and restaurant businesses - with prices, respectively, $p_{1} \geq 0$ i $p_{2} \geq 0$. Demand for the services of each of the enterprises of the hotel and restaurant business $Q_{1}\left(p_{1}, p_{2}\right) \geq 0, Q_{2}\left(p_{1}, p_{2}\right) \geq 0$ depends not only on the price of the enterprise of the hotel and restaurant business, but also on the price of the enterprises of the hotel and restaurant business - a competitor, and $Q_{1}\left(p_{1}, p_{2}\right)$ drops by $p_{1}$ at the given $p_{2}$ and growing by $p_{2}$ at this $p_{1}$, and $Q_{2}\left(p_{1}, p_{2}\right)$, on the contrary, drops by $p_{2}$ at this $p_{1}$ and growing by $p_{1}$ at this $p_{2}$.

According to modern domestic realities, the volume of their services is determined by the demand for them, with sufficient capacity to provide services to the hotel and restaurant business. Therefore, the average (specific) costs of each of the enterprises of the hotel and restaurant business $z_{1}\left(Q_{1}\left(p_{1}, p_{2}\right)\right) \geq 0, z_{2}\left(Q_{2}\left(p_{1}, p_{2}\right)\right) \geq 0$, customer service depends on the exact quantities of demand (they are the volume of services provided), $Q_{1}\left(p_{1}, p_{2}\right), Q_{2}\left(p_{1}, p_{2}\right)$, that is, indirectly from the same prices $p_{1}$ and $p_{2}$.

\section{Integration of two hotel and restaurant businesses (common case)}

In the case of integration of the hotel and restaurant business enterprises (managing them from a single coordinating center, common economic interests), their total profit will be

$$
\begin{aligned}
& F\left(p_{1}, p_{2}\right)=\left(p_{1}-z_{1}\left(Q_{1}\left(p_{1}, p_{2}\right)\right)\right) \cdot Q_{1}\left(p_{1}, p_{2}\right)+\left(p_{2}-z_{2}\left(Q_{2}\left(p_{1}, p_{2}\right)\right)\right) . \\
& Q_{2}\left(p_{1}, p_{2}\right) \rightarrow \max _{p_{1}, p_{2}}
\end{aligned} .
$$

To find the optimal, we equate to zero derivatives

$$
\begin{gathered}
\frac{\partial F}{\partial p_{1}}=\left(1-\frac{d z_{1}}{d Q_{1}} \cdot \frac{\partial Q_{1}}{\partial p_{1}}\right) \cdot Q_{1}+\left(p_{1}-z_{1}\right) \cdot \frac{\partial Q_{1}}{\partial p_{1}}-\frac{d z_{2}}{d Q_{2}} \cdot \frac{\partial Q_{2}}{\partial p_{1}} \cdot Q_{2}+ \\
+\left(p_{2}-z_{2}\right) \cdot \frac{\partial Q_{2}}{\partial p_{1}}=0
\end{gathered}
$$




$$
\begin{gathered}
\frac{\partial F}{\partial p_{2}}=\left(1-\frac{d z_{2}}{d Q_{2}} \cdot \frac{\partial Q_{2}}{\partial p_{2}}\right) \cdot Q_{2}+\left(p_{2}-z_{2}\right) \cdot \frac{\partial Q_{2}}{\partial p_{2}}-\frac{d z_{1}}{d Q_{1}} \cdot \frac{\partial Q_{1}}{\partial p_{2}} \cdot Q_{1}+ \\
+\left(p_{1}-z_{1}\right) \cdot \frac{\partial Q_{1}}{\partial p_{2}}=0 .
\end{gathered}
$$

Solving system (2) - (3), we obtain optimality conditions

$$
\begin{gathered}
p_{1}=z_{1}+\frac{d z_{1}}{d Q_{1}} \cdot Q_{1}+\frac{\frac{\partial Q_{2}}{\partial p_{1}} \cdot Q_{2}-\frac{\partial Q_{2}}{\partial p_{2}} \cdot Q_{1}}{\frac{\partial Q_{1}}{\partial p_{1}} \cdot \frac{\partial Q_{2}}{\partial p_{2}}-\frac{\partial Q_{2}}{\partial p_{1}} \cdot \frac{\partial Q_{1}}{\partial p_{2}}} \\
p_{2}=z_{2}+\frac{d z_{2}}{d Q_{2}} \cdot Q_{2}+\frac{\frac{\partial Q_{1}}{\partial p_{2}} \cdot Q_{1}-\frac{\partial Q_{1}}{\partial p_{1}} \cdot Q_{2}}{\frac{\partial Q_{1}}{\partial p_{1}} \cdot \frac{\partial Q_{2}}{\partial p_{2}}-\frac{\partial Q_{2}}{\partial p_{1}} \cdot \frac{\partial Q_{1}}{\partial p_{2}}}
\end{gathered}
$$

Note that expressions (4) and (5) have the same denominator

$$
\frac{\partial Q_{1}}{\partial p_{1}} \cdot \frac{\partial Q_{2}}{\partial p_{2}}-\frac{\partial Q_{2}}{\partial p_{1}} \cdot \frac{\partial Q_{1}}{\partial p_{2}}
$$

which is the Jacobian of a system of two functions $Q_{1}\left(p_{1}, p_{2}\right)$ i $Q_{2}\left(p_{1}, p_{2}\right)$.

Since the demand for the services of this hotel and restaurant business is more responsive to the change in the price of the hotel and restaurant business than the prices of the hotel and restaurant business competitor, that is

$$
\left|\frac{\partial Q_{1}}{\partial p_{1}}\right|>\left|\frac{\partial Q_{1}}{\partial p_{2}}\right|,\left|\frac{\partial Q_{2}}{\partial p_{2}}\right|>\left|\frac{\partial Q_{2}}{\partial p_{1}}\right|,
$$

then the Jacobian is positive. The same result (the addition of Jacobian) is ensured by another natural assumption that a single change in the price of a hotel and restaurant business will have a greater impact on the demand for the services of that hotel and restaurant business than a competitor of a hotel and restaurant business, that is

$$
\left|\frac{\partial Q_{1}}{\partial p_{1}}\right|>\left|\frac{\partial Q_{2}}{\partial p_{1}}\right|,\left|\frac{\partial Q_{2}}{\partial p_{2}}\right|>\left|\frac{\partial Q_{1}}{\partial p_{2}}\right| .
$$


Due to the properties of demand functions discussed above

$$
\frac{\partial Q_{2}}{\partial p_{1}}>0, \frac{\partial Q_{2}}{\partial p_{2}}<0, \frac{\partial Q_{1}}{\partial p_{2}}>0, \frac{\partial Q_{1}}{\partial p_{1}}<0
$$

which provides the addition of the numerators of the corresponding fractions of (4) and (5), whose denominators are Jacobian.

Thus, according to (4) and (5), the optimal prices are formed by setting a certain positive premium (third addition) to the average cost (first addition). The second addition implies an additional premium (if the average cost increases with the increase in the volume of services, ie marginal costs higher than the average) or a discount (if the average cost increases with the increase in the volume of services, the marginal costs below the average - up to a certain limit of increasing the volume of services may be a scale effect) to the optimum price of each hotel and restaurant business.

\section{Price competition of two hotel and restaurant enterprises (general case)}

If the hotel and restaurant business is independent, then each of them maximizes their profit (not the total profit of the hotel and restaurant business system):

$$
\begin{aligned}
& F_{1}\left(p_{1}, p_{2}\right)=\left(p_{1}-z_{1}\left(Q_{1}\left(p_{1}, p_{2}\right)\right)\right) \cdot Q_{1}\left(p_{1}, p_{2}\right) \rightarrow \max _{p_{1}}, \\
& F_{2}\left(p_{1}, p_{2}\right)=\left(p_{2}-z_{2}\left(Q_{2}\left(p_{1}, p_{2}\right)\right)\right) \cdot Q_{2}\left(p_{1}, p_{2}\right) \rightarrow \max _{p_{2}} .
\end{aligned}
$$

We equate the corresponding derivatives to zero:

$$
\begin{gathered}
\frac{\partial F_{1}}{\partial p_{1}}=\left(1-\frac{d z_{1}}{d Q_{1}} \cdot \frac{\partial Q_{1}}{\partial p_{1}}\right) \cdot Q_{1}+\left(p_{1}-z_{1}\right) \cdot \frac{\partial Q_{1}}{\partial p_{1}}=0, \\
\frac{\partial F_{2}}{\partial p_{2}}=\left(1-\frac{d z_{2}}{d Q_{2}} \cdot \frac{\partial Q_{2}}{\partial p_{2}}\right) \cdot Q_{2}+\left(p_{2}-z_{2}\right) \cdot \frac{\partial Q_{2}}{\partial p_{2}}=0,
\end{gathered}
$$

hence the Kurne equilibrium state of the system of two enterprises of the hotel and restaurant business, their prices must meet the conditions

$$
\begin{aligned}
& p_{1}=z_{1}+\frac{d z_{1}}{d Q_{1}} \cdot Q_{1}+\frac{Q_{1}}{\partial Q_{1} / \partial p_{1}}, \\
& p_{2}=z_{2}+\frac{d z_{2}}{d Q_{2}} \cdot Q_{2}+\frac{Q_{2}}{\partial Q_{2} / \partial p_{2}} .
\end{aligned}
$$


We see that the first two additions of the equilibrium prices (6) and (7) coincide with the corresponding components of the optimal prices (4) and (5). The differences between the equilibrium and optimal prices are due to the third additions to these expressions.

We also point out that neither (6) nor (7), nor (4) and (5) are calculation formulas for finding optimal or equilibrium prices - they merely express the conditions, respectively, of optimality or equilibrium of prices of the hotel and restaurant business.

\section{Linear statement of the problem}

To obtain the same calculation formulas and then compare the optimal and equilibrium states, we assume the additional simplifying assumption of linearity of all the dependencies used in the model.

Then, $Q_{1}\left(p_{1}, p_{2}\right)=q_{1}-k_{1} \cdot p_{1}+a_{1} \cdot p_{2}$

$$
Q_{2}\left(p_{1}, p_{2}\right)=q_{2}-k_{2} \cdot p_{2}+a_{2} \cdot p_{1},
$$

where $q_{1}>0, q_{2}>0$ - basic volumes of demand for services of the first and second enterprises of the hotel and restaurant business respectively;

$p_{1} \geq 0, p_{2} \geq 0$ - as before, prices for services of the first and second enterprises of the hotel and restaurant business;

$k_{1}>0, k_{2}>0$ - indicators of elasticity of demand for services of the first and second enterprises of the hotel and restaurant business at the price for these services;

$a_{1} \geq 0, a_{2} \geq 0$ - indicators of cross elasticity of demand for services of the first and second enterprises of the hotel and restaurant business at the price of services of competing enterprises of the hotel and restaurant business.

In order for the introduced linear functions to have the characteristics previously discussed (when considering the general case), the following relations must be performed between the parameters of these functions:

$k_{1}>a_{1}, k_{2}>a_{2}-$ a single change in the price of this enterprise of the hotel and restaurant business should have a more significant impact on the demand for its services than a single change in the price of competitors in the hotel and restaurant business;

$k_{1}>a_{2}, k_{2}>a_{1}-$ a single change in the price of a hotel and restaurant business should have a more significant effect on the demand for its services than on the demand for services of a hotel and restaurant business competitor.

The basic view of these dependencies is presented in Figs. 1-4. 


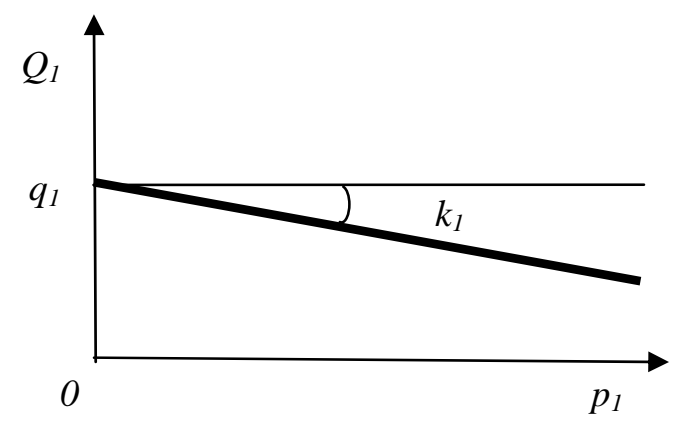

Fig. 1. Dependence of volume of services of the first enterprise of hotel and restaurant business $Q_{1}$ on own price $p_{1}$

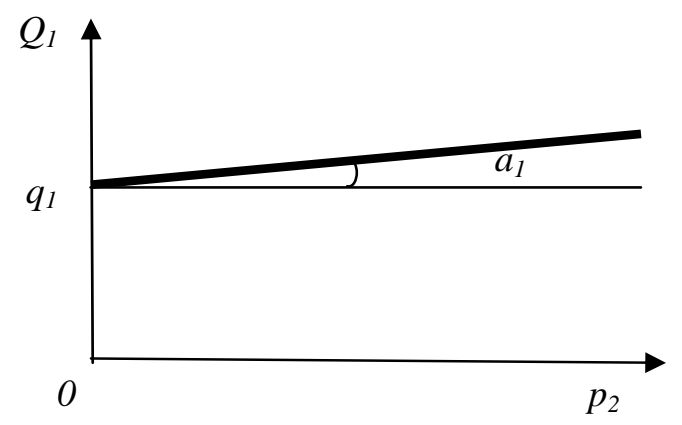

Fig. 2. Dependence of the volume of services of the first enterprise of hotel and restaurant business $Q_{1}$ on the price of competitor $p_{2}$

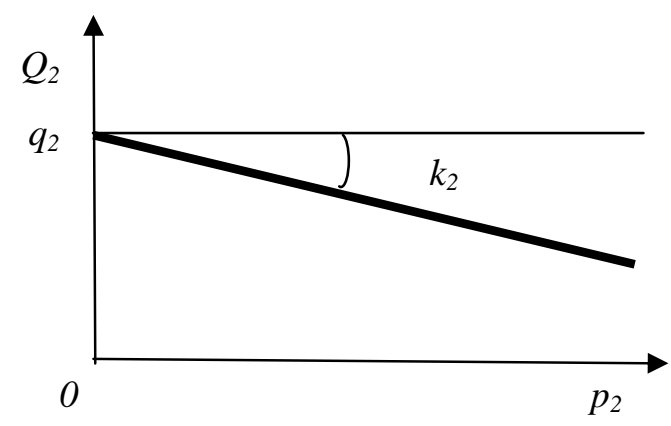

Fig. 3. Dependence of volume of services of the second enterprise of hotel and restaurant business $Q_{2}$ on own price $p_{2}$

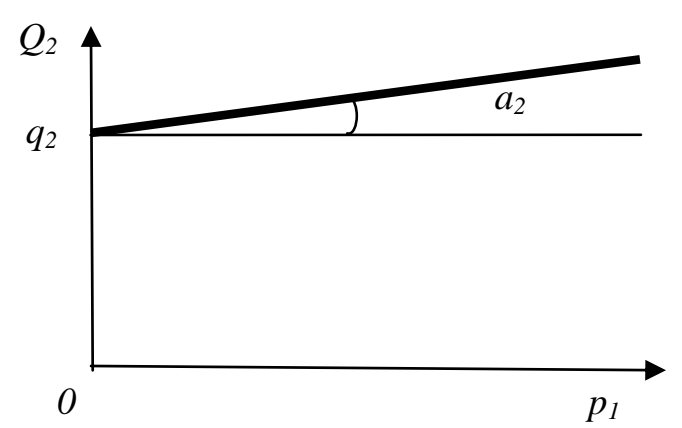

Fig. 4. Dependence of volume of services of the second enterprise of hotel and restaurant business $Q_{2}$ on the price of competitor $p_{1}$ 
To ensure that there is a strong demand for hotel and restaurant business services $Q_{1}\left(p_{1}, p_{2}\right) \geq 0, Q_{2}\left(p_{1}, p_{2}\right) \geq 0$ their price ratio should satisfy double inequality $\left(k_{2} \cdot p_{2}-q_{2}\right) / a_{2} \leq p_{1} \leq\left(q_{1}+a_{1} \cdot p_{2}\right) / k_{1}$.

As before, we will assume that the potential of providing services to the hotel and restaurant business is sufficient to meet the possible demand for their services, that is, the actual volume of services is determined exactly by the amount of demand and, accordingly, $Q_{1}\left(p_{1}, p_{2}\right)$ and $Q_{2}\left(p_{1}, p_{2}\right)$ (such an assumption is completely in line with current domestic economic realities).

With the linear nature of the cost of providing services, the specific cost is constant: $z_{1}\left(Q_{1}\left(p_{1}, p_{2}\right)\right)=z_{1}, z_{2}\left(Q_{2}\left(p_{1}, p_{2}\right)\right)=z_{2}$.

\section{Integration of two hotel and restaurant businesses (linear case)}

In the case of integration (integration of interests) of the enterprises of the hotel and restaurant business, they jointly maximize the total profit

$$
F=\left(p_{1}-z_{1}\right) \cdot\left(q_{1}-k_{1} \cdot p_{1}+a_{1} \cdot p_{2}\right)+\left(p_{2}-z_{2}\right) \cdot\left(q_{2}-k_{2} \cdot p_{2}+a_{2} \cdot p_{1}\right) \rightarrow \max _{p_{1}, p_{2}}
$$

To find the optimum, we equate partial derivatives to zero

$$
\begin{gathered}
\partial F / \partial p_{1}=q_{1}-2 k_{1} p_{1}+k_{1} z_{1}+a_{1} p_{2}+a_{2} p_{2}-a_{2} z_{2}=0 \\
\partial F / \partial p_{2}=q_{2}-2 k_{2} p_{2}+k_{2} z_{2}+a_{2} p_{1}+a_{1} p_{1}-a_{1} z_{1}=0,
\end{gathered}
$$

for the solution of this system the optimal prices of the enterprises of the hotel and restaurant business

$$
\begin{aligned}
& p_{1}^{0}=z_{1}+\frac{2 k_{2} q_{1}-2 k_{1} k_{2} z_{1}+a_{1} z_{2} k_{2}+a_{1} q_{2}+a_{1} a_{2} z_{1}+a_{2} q_{2}-a_{2} k_{2} z_{2}+a_{2}^{2} z_{1}}{4 k_{1} k_{2}-\left(a_{1}+a_{2}\right)^{2}}, \\
& p_{2}^{0}=z_{2}+\frac{2 k_{1} q_{2}-2 k_{1} k_{2} z_{2}+a_{2} z_{1} k_{1}+a_{2} q_{1}+a_{1} a_{2} z_{2}+a_{1} q_{1}-a_{1} k_{1} z_{1}+a_{1}^{2} z_{2}}{4 k_{1} k_{2}-\left(a_{1}+a_{2}\right)^{2}},
\end{aligned}
$$

The suitability of the denominators (8), (9) is ensured by the conditions discussed above $k_{1}>a_{1}, k_{2}>a_{2}, k_{1}>a_{2}, k_{2}>a_{1}$.

Substituting the found optimal values of prices (8) in the function of demand for services of the enterprises of the hotel and restaurant business, we obtain the optimum values of service rendering of each of the enterprises of the hotel and restaurant business:

$$
Q_{1}^{0}=\frac{\left(k_{1} k_{2}-a_{1} a_{2}\right)\left(q_{1}-2 k_{1} z_{1}+a_{1} z_{2}+a_{2} z_{2}\right)+\left(k_{1} k_{2}-a_{2}^{2}\right) q_{1}+\left(k_{1} a_{1}-k_{1} a_{2}\right) q_{2}}{4 k_{1} k_{2}-\left(a_{1}+a_{2}\right)^{2}}
$$




$$
Q_{2}^{0}=\frac{\left(k_{1} k_{2}-a_{1} a_{2}\right)\left(q_{2}-2 k_{2} z_{2}+a_{1} z_{1}+a_{2} z_{1}\right)+\left(k_{1} k_{2}-a_{1}^{2}\right) q_{2}+\left(k_{2} a_{2}-k_{2} a_{1}\right) q_{1}}{4 k_{1} k_{2}-\left(a_{1}+a_{2}\right)^{2}}
$$

Then the optimum total profit of the system of enterprises of the hotel and restaurant business

$$
F^{0}=\left(p_{1}^{0}-z_{1}\right) \cdot Q_{1}^{0}+\left(p_{2}^{0}-z_{2}\right) \cdot Q_{2}^{0}
$$

\section{Price competition between two hotel and restaurant businesses (Cournot equilibrium)}

In the case of competition from the hotel and restaurant business, each of them maximizes their own profit

$$
\begin{aligned}
& F_{1}=p_{1} \cdot Q_{1}-z_{1} \cdot Q_{1}=\left(p_{1}-z_{1}\right) \cdot\left(q_{1}-k_{1} \cdot p_{1}+a_{1} \cdot p_{2}\right) \rightarrow \max _{p_{1}}, \\
& F_{2}=p_{2} \cdot Q_{2}-z_{2} \cdot Q_{2}=\left(p_{2}-z_{2}\right) \cdot\left(q_{2}-k_{2} \cdot p_{2}+a_{2} \cdot p_{1}\right) \rightarrow \max _{p_{2}} .
\end{aligned}
$$

We find the first derivatives and equate them to zero:

$$
\begin{gathered}
d F_{1} / d p_{1}=q_{1}-2 k_{1} p_{1}+k_{1} z_{1}+a_{1} p_{2}=0, \\
d F_{2} / d p_{2}=q_{2}-2 k_{2} p_{2}+k_{2} z_{2}+a_{2} p_{1}=0,
\end{gathered}
$$

from here

$$
\begin{gathered}
p_{1}=\left(q_{1}+k_{1} z_{1}+a_{1} p_{2}\right) /\left(2 k_{1}\right), \\
p_{2}=\left(q_{2}+k_{2} z_{2}+a_{2} p_{1}\right) /\left(2 k_{2}\right) .
\end{gathered}
$$

Substituting the functions of the optimal reaction of the price of the hotel and restaurant business to the price of the hotel and restaurant business (10) and (11) one to another, we obtain the final expressions for the equilibrium prices of the hotel and restaurant business:

$$
\begin{aligned}
& p_{1}^{K}=z_{1}+\frac{2 k_{2} q_{1}-2 k_{1} k_{2} z_{1}+a_{1} z_{2} k_{2}+a_{1} q_{2}+a_{1} a_{2} z_{1}}{4 k_{1} k_{2}-a_{1} a_{2}}, \\
& p_{2}^{K}=z_{2}+\frac{2 k_{1} q_{2}-2 k_{1} k_{2} z_{2}+a_{2} z_{1} k_{1}+a_{2} q_{1}+a_{1} a_{2} z_{2}}{4 k_{1} k_{2}-a_{1} a_{2}} .
\end{aligned}
$$


Substituting these values in the function of demand for services of the enterprises of the hotel and restaurant business, we obtain

$$
\begin{aligned}
& Q_{1}^{K}=\frac{k_{1} \cdot\left(2 k_{2} q_{1}-2 k_{1} k_{2} z_{1}+a_{1} z_{2} k_{2}+a_{1} q_{2}+a_{1} a_{2} z_{1}\right)}{4 k_{1} k_{2}-a_{1} a_{2}}=k_{1} \cdot\left(p_{1}^{K}-z_{1}\right), \\
& Q_{2}^{K}=\frac{k_{2} \cdot\left(2 k_{1} q_{2}-2 k_{1} k_{2} z_{2}+a_{2} z_{1} k_{1}+a_{2} q_{1}+a_{1} a_{2} z_{2}\right)}{4 k_{1} k_{2}-a_{1} a_{2}}=k_{2} \cdot\left(p_{2}^{K}-z_{2}\right),
\end{aligned}
$$

then the Cournot equilibrium profits of the hotel and restaurant business

$$
\begin{aligned}
& F_{1}^{K}=\frac{k_{1} \cdot\left(2 k_{2} q_{1}-2 k_{1} k_{2} z_{1}+a_{1} z_{2} k_{2}+a_{1} q_{2}+a_{1} a_{2} z_{1}\right)^{2}}{\left(4 k_{1} k_{2}-a_{1} a_{2}\right)^{2}}=k_{1} \cdot\left(p_{1}^{K}-z_{1}\right)^{2}, \\
& F_{2}^{K}=\frac{k_{1} \cdot\left(2 k_{1} q_{2}-2 k_{1} k_{2} z_{2}+a_{2} z_{1} k_{1}+a_{2} q_{1}+a_{1} a_{2} z_{2}\right)^{2}}{\left(4 k_{1} k_{2}-a_{1} a_{2}\right)^{2}}=k_{2} \cdot\left(p_{2}^{K}-z_{2}\right)^{2},
\end{aligned}
$$

\section{Price competition between two hotel and restaurant businesses (equilibrium}

\section{by Stackelberg)}

To find the same equilibrium according to Stackelberg we will assume that one of the enterprises of the hotel and restaurant business (for certainty - the first) acts as a leader (active side), and the second - a successor. A leader, knowing the function of the optimal follower response (11) to its price, can use this information, substituting (11) into its target profit function and maximizing it now as a function of only one of its variables $p_{1}$, which no longer depends on $p_{2}$ :

$$
\begin{gathered}
F_{1}=\left(p_{1}-z_{1}\right) \cdot\left(q_{1}-k_{1} \cdot p_{1}+a_{1} \cdot p_{2}\right)= \\
=\left(p_{1}-z_{1}\right) \cdot\left(q_{1}-k_{1} \cdot p_{1}+a_{1} \cdot\left(q_{2}+k_{2} z_{2}+a_{2} p_{1}\right) /\left(2 k_{2}\right)\right) \rightarrow \max _{p_{1}} .
\end{gathered}
$$

Then $d F_{1} / d p_{1}=q_{1}-k_{1} \cdot p_{1}+a_{1} \cdot\left(q_{2}+k_{2} z_{2}+a_{2} p_{1}\right) /\left(2 k_{2}\right)+$ $+\left(p_{1}-z_{1}\right) \cdot\left(-k_{1}+a_{1} \cdot a_{2} /\left(2 k_{2}\right)\right)=0$,

hence the optimal leader price

$$
p_{1}^{S 1}=z_{1}+\frac{2 k_{2} q_{1}-2 k_{1} k_{2} z_{1}+a_{1} z_{2} k_{2}+a_{1} q_{2}+a_{1} a_{2} z_{1}}{4 k_{1} k_{2}-2 a_{1} a_{2}}
$$

Comparing (18) with (12), we see that with the same numerator the denominator in (18) is smaller, therefore, a fraction larger, so the equilibrium price of 
a leader on Stackelberg is always higher than its price in the Cournot equilibrium. Thus, in an effort to achieve higher profits than in the Kurno tolerance equilibrium, an active hotel and restaurant business will increase its price itself - in the expectation that it will subsequently increase its price and a hotel and restaurant business follower, thereby reducing the demand for the services of the hotel and restaurant business leader, due to the switchover, will not be so significant, and by means of a more substantial (compared to lower demand) price increase it is possible to increase the leader's profit.

Substituting (18) into (11) now, we obtain the equilibrium price of the Stackelberg follower:

$$
\begin{gathered}
p_{2}^{S 1}=z_{2}+\frac{2 k_{1} q_{2}-2 k_{1} k_{2} z_{2}+a_{2} z_{1} k_{1}+a_{2} q_{1}+a_{1} a_{2} z_{2}}{4 k_{1} k_{2}-2 a_{1} a_{2}}- \\
-\frac{a_{1} a_{2} \cdot\left(q_{2}+a_{2} z_{1}-k_{2} z_{2}\right)}{2 k_{2} \cdot\left(4 k_{1} k_{2}-2 a_{1} a_{2}\right)} .
\end{gathered}
$$

Comparing (19) with (18), we see that the first two additions are identical (up to indexes), but (19) also subtracts some value. It is for this value that the price of the second hotel and restaurant business as a follower for Stackelberg will be lower than the price of the same hotel and restaurant business as a leader for Stackelberg.

Comparison of optimal and equilibrium prices in the system of two enterprises of the hotel and restaurant business

We see that all prices - both optimal and different equilibrium - include the corresponding cost plus some rate of return. For the convenience of comparisons of the found optimal and equilibrium prices, we assume that PGRB are in absolutely equal conditions, that is

$$
q_{1}=q_{2}=q, k_{1}=k_{2}=k, a_{1}=a_{2}=a, z_{1}=z_{2}=z .
$$

Then optimal prices

$$
p_{1}^{0}=p_{2}^{0}=z+\frac{2 k q-2 k^{2} z+2 a q+2 a^{2} z}{4 k^{2}-4 a^{2}}
$$

prices, equilibrium for Cournot

$$
p_{1}^{K}=p_{2}^{K}=z+\frac{2 k q-2 k^{2} z+a q+a^{2} z+a z k}{4 k^{2}-a^{2}}
$$

the equilibrium price of the hotel and restaurant business leader in Stackelberg 


$$
p_{1}^{S 1}=z+\frac{2 k q-2 k^{2} z+a q+a^{2} z+a z k}{4 k^{2}-2 a^{2}},
$$

the equilibrium price of the hotel and restaurant business follower of Stackelberg

$$
p_{2}^{S 1}=z+\frac{2 k q-2 k^{2} z+a q+a^{2} z+a z k}{4 k^{2}-2 a^{2}}-\frac{a^{2} \cdot(q+a z-z k)}{2 k \cdot\left(4 k^{2}-2 a^{2}\right)} .
$$

Comparing, for example, (20) and (21), we see that the denominator in (20) is smaller and the numerator (20) - compared to (21) is added

$$
a q+a^{2} z-a z k=a(q-k z+a z)=a Q(z, z)>0,
$$

so $p_{1}^{K}=p_{2}^{K}<p_{1}^{0}=p_{2}^{0}$.

The denominator in (20) is smaller than in (22), and the numerator in (20) is greater than just shown - since the numbers in (22) and (21) are equal, it turns out

$$
p_{1}^{S 1}<p_{1}^{0}=p_{2}^{0}
$$

Because $a^{2} \cdot(q+a z-z k)=a^{2} \cdot Q(z, z)>0,4 k^{2}-2 a^{2}>0$, then

$$
p_{2}^{S 1}<p_{1}^{S 1}
$$

In (21) and (22) everything is the same except for the denominator, which in (21) is larger, therefore,

$$
p_{1}^{K}=p_{2}^{K}<p_{1}^{S 1}
$$

It remains to compare (21) and (23):

$$
p_{2}^{S 1}-p_{2}^{K}=\frac{a^{3} \cdot(a+2 k) \cdot(q-k z+a z)}{2 k \cdot\left(4 k^{2}-2 a^{2}\right) \cdot\left(4 k^{2}-a^{2}\right)}>0
$$

Thus, the following relationships are established between the optimal and different equilibrium prices of the hotel and restaurant business:

$$
p_{1}^{K}=p_{2}^{K}<p_{2}^{S 1}<p_{1}^{S 1}<p_{1}^{0}=p_{2}^{0}
$$


The lowest prices in the hotel and restaurant business are the tolerant competitors for Cournot. If one of the hotel and restaurant businesses behaves actively as a leader in Stackelberg, then in the new equilibrium the prices of both competing hotel and restaurant businesses rise, with the leader's price increasing more than the price of the follower. Finally, the highest prices are set in a state of optimum, with the integration (coordination of actions) of the hotel and restaurant business.

Numerical illustration of comparisons of different states are in the system of two enterprises of the hotel and restaurant business.

Let us illustrate the results obtained in the numerical example at $q_{1}=100$, $q_{2}=150, k_{1}=2, k_{2}=3, a_{1}=1, a_{2}=1,2, z_{1}=15, z_{2}=20$ (Table 1).

The table includes additional notations for the total volume of services provided $Q=Q_{1}+Q_{2}$ and total profit $F=F_{1}+F_{2}$ systems of two enterprises of the hotel and restaurant business.

Stackelberg 1 - stands for Stackelberg equilibrium with the leader - the first hotel and restaurant business;

Stackelberg 2 - a similar balance with the leader - the second hotel and restaurant business;

Quasi-optimum1 - a condition in which the second hotel and restaurant business adheres to the reached agreements on optimal prices, and the first hotel and restaurant business deviates from them in the most advantageous way for themselves;

Quasi-optimum2 is a similar state, when the first hotel and restaurant business executes the agreements, and deviates from them with the greatest benefit for itself the second;

The quasi-optimum is a condition where, in the same way (assuming that another hotel and restaurant business will comply with optimal price agreements), both hotel and restaurant businesses are simultaneously rejected from the optimum.

Table 1

\section{Numerical characteristics of optimal, equilibrium and quasi-optimal states of the system of two enterprises of the hotel and restaurant business}

\begin{tabular}{|l|c|c|c|c|c|c|c|c|}
\hline State of the system & $p_{1}$ & $p_{2}$ & $Q_{1}$ & $Q_{2}$ & $Q$ & $F_{1}$ & $F_{2}$ & $F$ \\
\hline Optimum & 55,6 & 52,9 & 41,7 & 58,1 & 99,8 & 1692,9 & 1909,0 & 3601,9 \\
\hline Courno & 43,4 & 43,7 & 56,8 & 71,1 & 127,9 & 1615,5 & 1682,8 & 3298,3 \\
\hline Stackelberg 1 & 45,0 & 44,0 & 54,0 & 72,0 & 126,0 & 1620,0 & 1728,0 & 3348,0 \\
\hline Stackelberg 2 & 43,8 & 45,0 & 57,5 & 67,5 & 125,0 & 1653,1 & 1687,5 & 3340,6 \\
\hline Quasioptimum 1 & 45,7 & 52,9 & 61,4 & 46,2 & 107,7 & 1887,5 & 1519,8 & 3407,3 \\
\hline Quasioptimum 2 & 55,6 & 46,1 & 34,9 & 78,4 & 113,3 & 1418,3 & 2046,3 & 3464,6 \\
\hline Quasioptimum & 45,7 & 46,1 & 54,7 & 66,5 & 121,2 & 1679,7 & 1737,1 & 3416,8 \\
\hline
\end{tabular}


Conclusion. The coincidence of the results of the calculations obtained with the option «Finding the solution» of the MS Excel package and using the deduced formulas, confirms the correctness of the latter.

We see that the best financial results for each hotel and restaurant business reaches its quasi-optimum, deviating from the reached agreements - despite the fact that another hotel and restaurant business adheres to them. This fact confirms the instability of the optimal condition - it is profitable for each of the enterprises of the hotel and restaurant business to deviate from it.

Further, in order of decreasing profitability for a given enterprise of the hotel and restaurant business, there are states of optimum, quasi-optimum, equilibrium according to Stackelberg (and the follower to be more profitable than the leader!), equilibrium for Cournot, finally, quasi-optimum of another enterprise of hotel and restaurant business. All to comply with their agreed high optimum price if another hotel and restaurant business breaks the arrangement in the most favorable manner for them.

Thus, in different equilibrium states, prices of hotel and restaurant businesses are lower, demand for their services and, consequently, volumes of their provision are higher, hotel and restaurant business profits are lower than in the state of optimum.

Thus, the competition of the hotel and restaurant business is beneficial to the consumers of their services, but not profitable to the hotel and restaurant business itself; unification of interests (coordination of actions) of the enterprises of the hotel and restaurant business increases the profit of each of them at the expense of consumers.

On the other hand, the equilibrium condition has the property of market stability it is not profitable to deviate from it by any of the enterprises of the hotel and restaurant business separately.

The optimal condition, on the contrary, is unstable - each of the enterprises of the hotel and restaurant business, reasonably deviating from it (provided that another enterprise of the hotel and restaurant business will maintain its optimal price), can further increase its profit - now at the expense of the offended enterprises of the hotel and restaurant business-competitor. Therefore, the optimal condition of the hotel and restaurant business system can only be realized when they are combined (coordinated) or directly.

\section{REFERENCES}

1. Bosovska M., Vedmid N., Kulyk M. - Tourist enterprises integration processes diagnostics and structuring. DOI: https://doi.org/10.32782/2524-0072/2019-20-19.

2. T. Russell Crook, David J. Ketchen, Charles C. Snow-The Cornell Hotel and Restaurant Administration Quarterly, Volume 44, Issue 3June 2003, Pages 44-53. 
3. M. Dibra. Rogers Theory on Diffusion of Innovation-The Most Appropriate Theoretical Model in the Study of Factors Influencing the Integration of Sustainability in Tourism Businesses.Procedia - Social and Behavioral Sciences, Volume 195, 3 July 2015, Pages 1453-1462.

4. Adriana F. Chim-Miki, Rosa M. Batista-Canino. Development of atourism coopetition model: A preliminary Delphi study. Journal of Hospitality and Tourism Management, Volume 3, 7 December 2018, Pages 78-88.

5. Bosovska, M. V. (2015), Integhracijni procesy $\mathrm{v}$ turyzmi [Integration processes in tourism], KNTEU, Kyiv, Ukraine.

6. A.George Assafa, Mike G.Tsionasb- Annals of Tourism Research Volume 76, May 2019, Pages 266-277.

7. Fatemeh Ahmadimanesh, Mohammad Mahdi Paydar, Ebrahim AsadiGangraj - Tourism Management, Volume 75, 2019, Pages 404-417, ISSN 0261-5177, https://doi.org/10.1016/j.tourman.2019.06.001

8. Anna Spenceley, Susan Snyman, Paul F.J.Eagles Journal of Outdoor Recreation and Tourism,Volume 26, June 2019, Pages 72-80

9. Sanaz Shafiee, Ali Rajabzadeh Ghatari, Alireza Hasanzadeh, Saeed Jahanyan. Developing a model for sustainable smart tourism destinations: A systematic review. Tourism Management Perspectives, Volume 3, 1 July 2019, Pages 287-300.

10. Libo Yan, Bo Wendy Gao, Meng Zhang A mathematical model for tourism potential assessment Tourism Management, Volume 6, 3 December 2017, Pages 355-365.

11. Varian H. Microeconomics. Intermediate level. The modern approach: Per. from English. - M.: UNITY, 1997. - 767 p.

12. Jehle G., Reny Ph. Advanced Microeconomic Theory. - Addison Wesley, 2000. $-560 \mathrm{p}$.

13. Varian H.R. Microeconomic Analysis. -W.W.Norton \& Company, 1992. $506 \mathrm{p}$.

14. Nicholson W. Intermediate Microeconomics and its Application. Harcourt, 2000. -640 p.

15. Mathis S., Koscianski J. Microeconomic Theory: An Integrated Approach. Prentice Hall, 2002. -681 p. 